\title{
openheart Adherence to coronary artery disease secondary prevention medicines: exploring modifiable barriers
}

\author{
Rani Khatib, ${ }^{\oplus, 2,3}$ Kay Marshall, ${ }^{4}$ Jon Silcock, ${ }^{5}$ Claire Forrest, ${ }^{3}$ Alistair S Hall ${ }^{2,3}$
}

To cite: Khatib R, Marshall K, Silcock J, et al. Adherence to coronary artery disease secondary prevention medicines: exploring modifiable barriers. Open Heart 2019;6:e000997. doi:10.1136/ openhrt-2018-000997

Received 17 December 2018 Revised 14 May 2019 Accepted 13 June 2019

Check for updates

(C) Author(s) (or their employer(s)) 2019. Re-use permitted under CC BY-NC. No commercial re-use. See rights and permissions. Published by BMJ.

${ }^{1}$ Medicines Management \& Pharmacy Services, Leeds Teaching Hospitals NHS Trust, Leeds, UK

${ }^{2}$ Cardiology Department, Leeds Teaching Hospitals NHS Trust, Leeds, UK

${ }^{3}$ Leeds Institute of

Cardiovascular and Metabolic Medicine, University of Leeds, Leeds, UK

${ }^{4}$ School of Health Sciences, University of Manchester,

Manchester, UK

${ }^{5}$ Bradford School of Pharmacy, University of Bradford, Bradford, UK

Correspondence to Dr Rani Khatib; r.khatib@leeds. ac.uk

\begin{abstract}
Background Non-adherence to secondary prevention medicines (SPMs) among patients with coronary artery disease $(C A D)$ remains a challenge in clinical practice. This study attempted to identify actual and potential modifiable barriers to adherence that can be addressed in cardiology clinical practice.
\end{abstract}

Methods This was a cross-sectional, postal survey-based study of the medicines-taking experience of patients with CAD treated at a secondary/tertiary care centre. All participants had been on SPM for $\geq 3$ months.

Results In total, 696 eligible patients were sent the survey and 503 responded (72.3\%). The median age was 70 years, and $403(80.1 \%)$ were male; the median number of individual daily doses of all medicines was 6 . The rate of non-adherence to at least one SPM was $43.5 \%(n=219)$, but $53.3 \%$ of reported non-adherence was to only one SPM. Statins contributed to $66.7 \%$ and aspirin to $61.7 \%$ of overall non-adherence identified by the Single Question (SQ) tool. In $30.8 \%$ of non-adherent patients $(n=65)$, this was at least partly intentional. Barriers included forgetfulness $(84.9 \% ; n=186)$, worry that medicines will do more harm than good $(33.8 \% ; n=74)$, feeling hassled about medicines taking $(18.7 \% ; n=41)$, feeling worse when taking medicines $(14.2 \% ; n=31)$ and not being convinced of the benefit of medicines $(9.1 \% ; n=20)$. In a multivariate analysis, modifiable factors associated with overall non-adherence included being prescribed aspirin (OR: 2.22; 95\% Cl: 1.18 to 4.17), having specific concern about SPM (OR: 1.12; 95\% Cl: 1.07 to 1.18 ) and issues with repeat prescriptions (OR: 2.48 ; $95 \% \mathrm{Cl}: 1.26$ to 4.90 ). Different factors were often associated with intentional versus unintentional non-adherence.

Conclusions Using appropriate self-report tools, patients share actual and potential modifiable barriers to adherence that can be addressed in clinical practice. Non-adherence behaviour was selective. Most non-adherence was driven by forgetfulness, concern about the harm caused by SPM and practical barriers.

\section{INTRODUCTION}

Patients with coronary artery disease (CAD) are typically prescribed secondary prevention medicines (SPMs), such as ACE inhibitors, angiotensin receptor blockers (ARBs), beta-blockers, statins, oral antiplatelet agents and/or aspirin. The benefits of SPMs are well

\section{Key questions}

What is already known about this subject?

- Up to $50 \%$ of patients with coronary artery disease (CAD) may be non-adherent to their secondary prevention medicines (SPMs). This can lead to poor control of risk factors, inappropriate therapeutic intensification, worse health outcomes, increased hospital readmissions and mortality and increased healthcare costs. Despite a plethora of research, non-adherence remains a key challenge in clinical practice. There is a need for a practical approach to enable appropriate targeting of interventions.

What does this study add?

- Based on a medicines-taking experience self-report, the rate of non-adherence with SPMs in patients with $\mathrm{CAD}$ was consistent with the literature. When prompted, patients shared actual and potential modifiable barriers to adherence that could be addressed in clinical practice. Non-adherence behaviour was selective and was mostly driven by forgetfulness, concern about the harm that can be caused by SPM and practical barriers.

How might this impact on clinical practice?

- Appropriate self-report screening tools can be used in clinical practice to identify modifiable barriers to adherence among patients with CAD. Healthcare professionals should elicit and explore their patients' beliefs and experiences with their medicines and tailor adherence interventions individually to overcome barriers.

established, and their use is recommended in national and international guidelines. ${ }^{1-3}$

However, non-adherence to medicinesincluding SPMs-remains a key challenge, limiting overall benefits and often leading to poor health outcomes, lower quality of life and increased demand for healthcare. ${ }^{4-6}$ A number of studies have reported high levels of non-adherence among patients with CAD, typically in the range of $33 \%-50 \% .^{5-10}$ Non-adherence to SPMs has been associated with a $10 \%-40 \%$ relative increase in the risk of cardiac hospitalisation and a $50 \%-80 \%$ relative increase in mortality. ${ }^{411} 12$ 
A number of factors need to be considered if we are to remedy this complex problem in clinical practice. ${ }^{5}$

First, the medicines-taking experience of patients should be routinely explored and modifiable barriers addressed. ${ }^{7}$ Non-adherence is often a hidden problem, under-recognised by prescribers and not necessarily disclosed by patients. ${ }^{13}$ Healthcare professionals should assess, elicit and explore patients' beliefs and experiences with their medicines to help them make informed choices and address any barriers. ${ }^{5}$ This requires the use of specific tools that can be deployed in clinical practice to explore and address barriers to medicines taking.

Second, patient self-reports may be the most useful tools for exploring adherence in clinical practice because they are inexpensive, pragmatic and more likely than other tools to reveal barriers. ${ }^{513}$ Social desirability and memory biases may lead to over-reporting of adherence, but self-reported non-adherence behaviour is broadly considered to be reliable and accurate. ${ }^{13-17}$

Third, non-adherence may be either intentional or unintentional,,$^{5}$ and these should be identified and addressed in different ways. Some patients may display both types simultaneously.

Fourth, the causes of non-adherence are complex, multifactorial and cannot be explained by single fixed factors-such as the type or severity of the disease or sociodemographics. ${ }^{13}$ Hence, there is no 'one size fits all' solution to address non-adherence. ${ }^{1317-19}$ The underlying causes of non-adherence need to be understood individually, and interventions tailored to the needs of the individual patient.

The great challenge is to implement this in clinical practice. Suitable self-report tools are needed that can identify actual and potential barriers to SPM adherence among patients with ischaemic heart disease. These instruments were lacking at the time the present study was initiated. Hence, multiple tools were used to assess various modifiable barriers to adherence. Understanding these barriers, as well as the performance of self-report tools in revealing the medicines-related issues faced by patients on SPM, will enable interventional studies in a clinical setting.

Based on the consideration of the four key factors described above, the first Reported Adherence versus Non-adherence Investigation (RANI-1) was designed to assess adherence rates with SPM among patients with CAD and to identify actual and potential modifiable barriers to adherence that can be addressed in cardiology clinical practice.

\section{METHODS}

\section{Study design}

This was a cross-sectional, survey-based study of the medicines-taking experience of patients with $\mathrm{CAD}$ treated at the Yorkshire Heart Centre, a secondary/tertiary care centre in Leeds, UK. It was performed between January 2010 and January 2011. A flow diagram summarising the

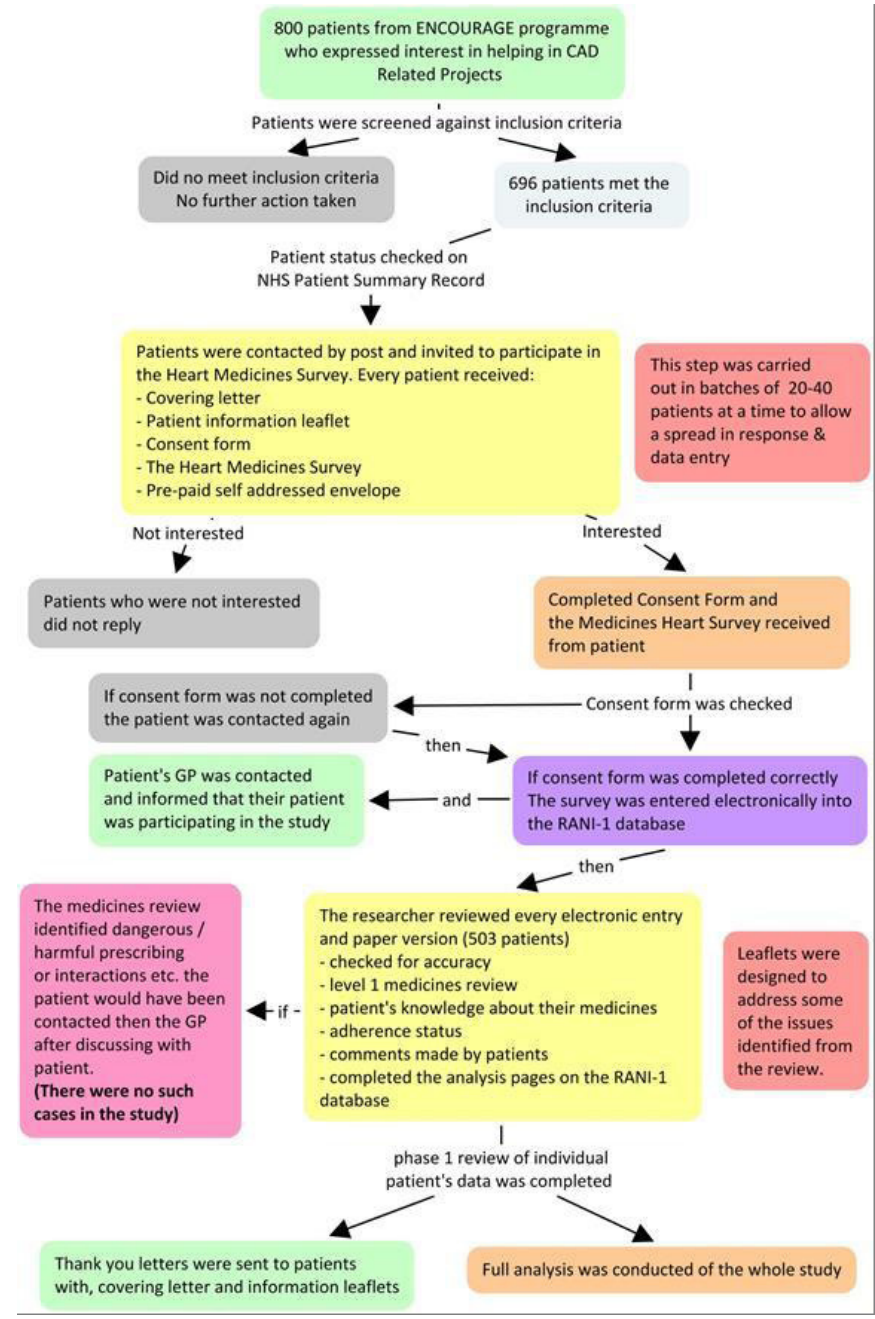

Figure 1 Flow diagram of study conduct. A level-1 medicines review includes screening for any apparent problems with prescribed medicines. CAD, coronary artery disease; ENCOURAGE, Epidemiology of Northern Cardiovascular Outcomes and Underlying Risk of Atherosclerosis due to Genes and Environment (programme database at the Yorkshire Heart Centre in Leeds, UK); GP, general practitioner; NHS, National Health Service; RANI-1, First Reported Adherence versus Non-adherence Investigation.

study conduct is provided in figure 1. Briefly, potential participants were sent a survey (known at that time as the Heart Medicines Survey) in the mail, along with explanatory information and a consent form, and were invited to return the completed materials in a prepaid envelope.

\section{Participants}

The survey was sent to patients from the West Yorkshire ENCOURAGE (Epidemiology of Northern Cardiovascular Outcomes and Underlying Risk of Atherosclerosis due to Genes and Environment) programme who had recently expressed an interest in heart-related healthcare improvement projects. All had established CAD, defined as documented or reported myocardial infarction, angioplasty and coronary artery bypass graft, or angina (positive 
exercise test). Eligible patients had been prescribed at least one SPM for $\geq 3$ months.

\section{Survey assessments}

Baseline data collected for individual patients included age, sex, relevant underlying conditions and previous procedures, the SPMs prescribed, the number of individual daily doses and the number of daily administration times.

The design of the survey itself was guided by a literature review, which identified several validated adherence assessment and exploratory tools. These were assessed for feasibility based on the ease of use in daily clinical practice, ability to identify modifiable barriers to adherence and ability to quantify levels of non-adherence. Four were included within the survey: the SQ tool, ${ }^{20}$ the eight-item CMorisky Medication Adherence Scale (MMAS-8), ${ }^{21}$ the Adherence Estimator (AE) ${ }^{22}$ and the Beliefs about Medicines Questionnaire (BMQ) ${ }^{23}$ Where applicable, permission from the developers was sought.

The SQ tool asks patients, 'In the past month, how often did you take your medications as the doctor prescribed?'. ${ }^{20}$ The tool was modified by asking participants to elaborate about individual medications. Scoring was based on a 5-point Likert scale (all the time, nearly all the time, most of the time, about half the time, less than half the time). Due to the low sensitivity of the SQ tool, patients were considered non-adherent if they selected any answer other than 'all the time'.

The MMAS- 8 uses eight questions to ask patients about forgetting to take medicines, not taking medicines for reasons other than forgetfulness, changing medicines due to feeling unwell or feeling that the condition is better controlled and feeling hassled about sticking to their treatment plan. ${ }^{21}$

Participants were asked to answer questions $1-7$ as 'yes' or 'no'; question 8 had a five-point Likert response scale (all the time, usually, sometimes, once in a while, never/rarely). The scoring was in line with the guidelines provided by the author of the tool.

The internal consistency and unidimensionality of the construct of the MMAS- 8 scale was examined using Cronbach's $\alpha$ statistics and factor analysis to exclude any problematic questions and identify multidimensionality. Question 5 was excluded because it caused low internal consistency. The original author of the MMAS- 8 tool was contacted and agreed with this exclusion.

Based on the findings of the factor analysis, the results from MMAS-8 were subdivided according to factor 1 questions that focus mainly on unintentional non-adherence (questions 1, 2, 4 and 8) and factor 2 questions that focus more on intentional non-adherence (questions 3, 6 and 7).

The AE is a non-adherence predicting tool, which asks patients to assess three statements on a 6-point Likert scale (from completely agree to completely disagree) ${ }^{22}$

1. I worry that my prescription medication will do more harm than good.
2. I am convinced of the importance of my prescription medication.

3. I feel financially burdened by my out-of-pocket expenses for my prescription medication.

All answers were scored as per guidelines provided by the author of the tool.

The BMQ is a tool with 18 questions divided into four groups $^{23}$ : the specific necessity for SPM; specific concern about SPM; general overuse of medicines and the general harm of medicines. Only responses to first two groups of questions were included in the present analysis. Mean scores (ranging from 5 to 25 , where $5=$ strongly disagree and $25=$ strongly agree) were calculated for patient beliefs about the specific necessity for taking SPM and specific concern about taking SPM.

Patients were also asked about potential practical barriers to adherence based on whether they had any problems with: opening the medicine bottle or blister pack, reading the label on the medicine bottle, swallowing medicines or getting a repeat prescription. Any patient who asked for an alternative was considered to 'Need a solution', regardless of the extent of the problem.

\section{Statistical analysis}

A power calculation was used to determine the required sample size. A total of 120-180 non-adherent patients was considered necessary to detect 1 unit change in the MMAS- 8 score (based on a power of $90 \%$ and $\alpha=0.05$ ). Levels of non-adherence in the literature are $33 \%-50 \% .^{5-10}$ Therefore, screening of 500 patients would be more than enough to identify sufficient non-adherent patients.

Simple descriptive statistics were used to elucidate the characteristics of the patient population and results from individual adherence tools.

Statistical analyses were performed using SPSS V.19 (IBM, Chicago, Illinois, USA). Differences between adherent and non-adherent patients were assessed using Mann-Whitney $\mathrm{U}$ test or independent-samples t-test, or $\chi^{2}$ test or Fisher's exact test, as appropriate. The independent-samples t-test was used to compare means of parametric data and the Mann-Whitney $U$ test for non-parametric or non-normally distributed data. The $\chi^{2}$ test or Fisher's exact test (if less than five cases were expected in any cell) were used for categorical data. $\mathrm{P}<0.05$ was considered statistically significant.

Multivariate analysis was undertaken using logistic regression. Three models were built for the following dependent variables: overall non-adherence according to MMAS-8 or SQ; factor 1 (unintentional) non-adherence; factor 2 (intentional) non-adherence. As recommended by statisticians and statistical books, ${ }^{24}{ }^{25}$ variables that had a $p$ value $<0.25$ in the univariate analysis for non-adherence were retained to include in the multivariate model. A correlation matrix (using Spearman's coefficient) was reviewed for any evidence of collinearity. ORs with $95 \%$ CIs were calculated. 


\begin{tabular}{|c|c|}
\hline Characteristic & $\begin{array}{l}\text { Patients } \\
(\mathrm{N}=503)\end{array}$ \\
\hline Age (years), median (range) & $70(38-92)$ \\
\hline Male sex, n (\%) & $403(80.1)$ \\
\hline \multicolumn{2}{|l|}{ Underlying conditions/procedures, $\mathrm{n}(\%)$} \\
\hline Myocardial infarction & $349(69.4)$ \\
\hline Angioplasty & $286(56.9)$ \\
\hline Coronary artery bypass graft & $192(38.2)$ \\
\hline Diabetes* $^{*}$ & $62(12.3)$ \\
\hline \multicolumn{2}{|l|}{ Secondary medicines prescribed, $\mathrm{n}(\%)$} \\
\hline Statin & $476(94.6)$ \\
\hline Aspirin & $439(87.3)$ \\
\hline Beta-blocker & $356(70.8)$ \\
\hline ACE inhibitor & $293(58.3)$ \\
\hline AllRA & $104(20.7)$ \\
\hline Clopidogrel & $59(11.7)$ \\
\hline Total number of medicinest, median (range) & $7(2-20)$ \\
\hline Number of individual daily doses, median (range) & $6(1-24)$ \\
\hline Number of daily administration times, median (range) & $2(1-4)$ \\
\hline \multicolumn{2}{|l|}{ Dosing frequency of medicines, $\mathrm{n}(\%)$} \\
\hline All once daily & $250(49.7)$ \\
\hline At least one medicine taken twice daily $\ddagger$ & $189(37.6)$ \\
\hline At least one medicine taken more than twice daily & $64(12.7)$ \\
\hline
\end{tabular}

*Prescribed antidiabetic medication.

†Includes all medicines and not just secondary prevention medicines.

$\ddagger$ And no medicines taken more than twice daily.

ACE, angiotensin converting enzyme; AlIRA, angiotensin II receptor antagonists.

\section{RESULTS}

\section{Patient characteristics}

Of the 696 patients who were sent the survey in the mail, $503(72.3 \%)$ returned the completed questionnaire. The demographic profile of these individuals is summarised in table 1 . The median age was 70 years (range: $38-92$ ), and 403 patients $(80.1 \%)$ were male. The median total number of medicines received (including non-SPM) was 7 (range: 2-20), and the median number of individual daily doses was 6 (range 1-24). The median number of daily administration times was twice daily (range: 1-4 times daily). In total, 27 patients (5.4\%) had been on SPM for 3-12 months; the other $476(94.6 \%)$ had been on at least one SPM for $>12$ months.

\section{Levels of adherence}

Considering responses to both the MMAS-8 and SQ elements of the survey, $56.5 \%$ of respondents $(n=284 / 503)$ appeared to be adherent with their medicines, whereas $43.5 \%(n=219 / 503)$ were non-adherent on one or both scales.
Table 2 Adherence levels

\begin{tabular}{lr}
\hline Adherence & Patients \\
\hline Overall (N=503) & \\
\hline Adherent & $284(56.5)$ \\
\hline Non-adherent & $219(43.5)$ \\
\hline Intentional versus unintentional non-adherence (N=211) & \\
$\quad$ Factor 1 (unintentional) non-adherence & $186(88.2)$ \\
\hline Factor 2 (intentional) non-adherence & $65(30.8)$ \\
\hline Both factor 1 and 2 non-adherence & $40(19.0)$ \\
\hline
\end{tabular}

All data are $n(\%)$. Overall adherence was assessed using both MMAS-8 and SQ. Intentional and unintentional non-adherence was assessed using MMAS-8 only.

MMAS-8, eight-item Morisky Medication Adherence Scale; SQ, Single Question.

The number of SPMs that non-adherent patients failed to adhere to was assessed using the modified SQ tool. In total, 482 respondents completed this part of the questionnaire. The sensitivity of the SQ tool to detect non-adherence is low, and hence overall levels of reported non-adherence were only $12.5 \% \quad(n=60 / 482)$. However, the responses suggested more than half of these patients $(53.3 \% ; \mathrm{n}=32 / 60)$ were non-adherent to only one SPM. The remainder were non-adherent to two $(18.3 \% ; \mathrm{n}=11)$, three $(11.7 \% ; n=7)$ or four $(16.7 \% ; n=10)$ SPMs. Among these 60 patients, the greatest contributors to overall non-adherence were statins $(66.7 \% ; \mathrm{n}=40)$, aspirin $(61.7 \% ; \mathrm{n}=37)$, beta-blockers $(30.0 \% ; \mathrm{n}=18)$, ACE inhibitors $(21.7 \%$; $n=13)$, clopidogrel $(6.7 \% ; n=4)$ and ARBs $(5.0 \% ; \mathrm{n}=3)$.

The MMAS- 8 data were also split according to factor 1 questions that focused mainly on unintentional non-adherence (eg, forgetfulness) and factor 2 questions that focused more on intentional non-adherence (eg, not taking medicines because it is a hassle). Among the 211 non-adherent patients, $88.2 \%(\mathrm{n}=186)$ displayed factor 1 (unintentional) non-adherence and $30.8 \% \quad(\mathrm{n}=65)$ showed factor 2 (intentional) non-adherence (table 2).

\section{Reasons for non-adherence}

The most common reasons for non-adherence as stated by patients were forgetfulness $(84.9 \% ; n=186)$, worry that their medicines will do more harm than good (33.8\%; $\mathrm{n}=74$ ), feeling hassled about sticking to the treatment plan $(18.7 \% ; \mathrm{n}=41)$, stopping medicine (s) without telling their doctor after feeling worse $(14.2 \%$; $n=31)$ and not feeling convinced enough about the importance of their medicines $(9.1 \%$; $\mathrm{n}=20)$ (table 3 ).

Patients were also asked about practical barriers to adherence (table 4$)$. In total, $22.4 \%$ of patients $(n=110)$ reported problems with opening bottles or blister packs, $8.2 \%(n=40)$ had a problem with reading the label, $8.6 \%$ $(n=42)$ had problems swallowing medicines and $10.4 \%$ $(n=51)$ had issues with getting repeat prescriptions. Problems with reading the label or with getting repeat prescriptions were significantly associated with overall 
Table 3 Reasons of non-adherence among non-adherent patients

\begin{tabular}{lr|}
\hline Reason & $\begin{array}{c}\text { Patients } \\
\text { (N=219) }\end{array}$ \\
\hline Forgetfulness of any type & $186(84.9)$ \\
\hline Forgetfulness when travelling & $26(11.9)$ \\
\hline Worry that their medicines will do more harm than good & $74(33.8)$ \\
\hline Hassled about medicines & $41(18.7)$ \\
\hline Stopped medicine(s) after feeling worse on medicine* & $31(14.2)$ \\
\hline Not convinced enough about the importance of their & $20(9.1)$ \\
medicines & \\
\hline $\begin{array}{l}\text { Stopped medicine(s) after feeling condition under control } \\
\text { Felt financially burdened by cost of medicines† }\end{array}$ & $5(2.3)$ \\
\hline
\end{tabular}

All data are $n(\%)$. Possible reasons for non-adherence were assessed based on responses to MMAS-8, SQ and AE. Patients could have more than one reason for non-adherence.

*Without telling doctor.

†Among 37 patients who were paying for their prescription(s). AE, Adherence Estimator; MMAS-8, eight-item Morisky Medication Adherence Scale; SQ, Single Question.

non-adherence. Moreover, all four of the practical problems assessed were significantly associated with factor 2 (intentional) non-adherence (table 4).

\section{Beliefs about medicines}

Belief about the specific necessity for taking SPMs was lower among non-adherent patients than among adherent individuals (mean score 19.32 vs 18.48 , respectively; $\mathrm{p}=0.016$ ) (table 5). In addition, levels of specific concern about taking their medicines were higher in non-adherent versus adherent patients (mean score 12.70 vs $10.67 ; \mathrm{p}<0.001$ ).

\section{Comparison of adherent and non-adherent patients}

Table 6 compares the characteristics of adherent and non-adherent patients according to a univariate model. Factor 1 (unintentional) non-adherence was associated with a number of variables, including younger age, male sex, a lower likelihood of diabetes or coronary artery bypass graft, fewer medicines and doses per day, a lower number of daily administration times and a greater probability of taking aspirin. Factor 2 (intentional) non-adherence was associated with a younger age, a greater number of medicines, a greater probability of taking aspirin and a lower probability of taking a beta-blocker.

In a multivariate model, factors significantly associated with factor 1 (unintentional) non-adherence included younger age, male sex, not being diabetic, no previous coronary artery bypass graft, being prescribed aspirin and greater specific concerns about their SPM medicines (table 7). Factors significantly associated with factor 2 (intentional) non-adherence included younger age, a greater number of prescribed medicines, not being prescribed a beta-blocker, being prescribed aspirin, lower belief in the specific necessity for their medicines, greater specific concerns about their medicines and issues

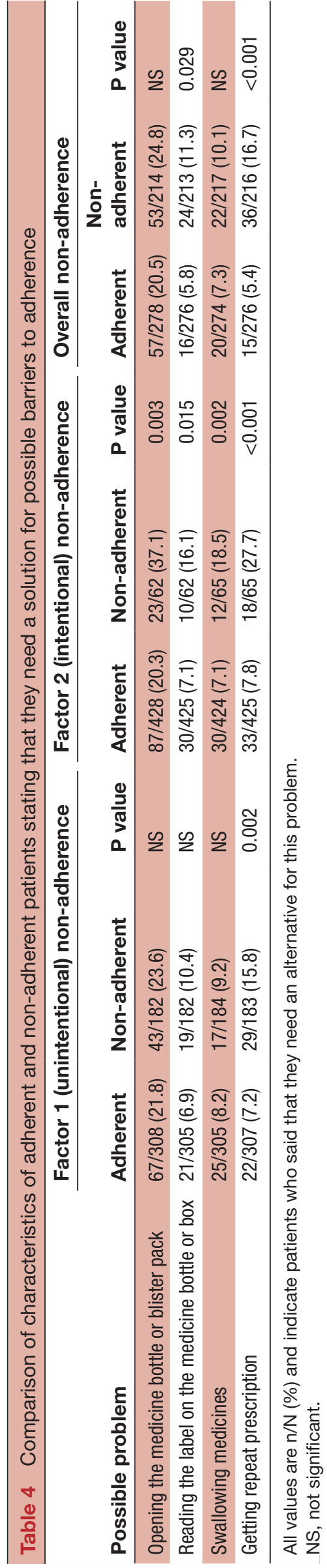




\begin{tabular}{lllcc}
\hline \multicolumn{2}{l}{ Table 5} & \multicolumn{1}{l}{ Beliefs about medicines among overall adherent and non-adherent patients } & \\
\hline BMQ domain & Adherent patients & Non-adherent patients & Mean difference & P value \\
\hline Specific necessity for taking SPM & $19.32(4.10)$ & $\begin{array}{l}18.48(3.60) \\
(\mathrm{N}=218)\end{array}$ & 0.85 & 0.016 \\
Specific concern about taking SPM & $(\mathrm{N}=281)$ & $\begin{array}{l}12.70(4.17) \\
(\mathrm{N}=216)\end{array}$ & -2.03 & $<0.001$ \\
& $(\mathrm{~N}=278)$ & $(4.17)$ &
\end{tabular}

Values given for each domain are mean scores (SD). Possible scores range from 5 to 25 , where $5=$ strongly disagree and $25=$ strongly agree. $\mathrm{BMQ}$, Beliefs about Medicines Questionnaire; SPM, secondary prevention medicine.

with getting repeat prescriptions. Finally, factors associated with any non-adherence-whether intentional or unintentional-included younger age, male sex, being prescribed aspirin, greater specific concern about their medicines and issues with getting repeat prescriptions (table 7).

\section{DISCUSSION}

This study found an overall level of non-adherence with SPMs in patients with CAD $(43.5 \%)$ that was broadly consistent with the literature, ${ }^{6-10}$ although the methods used to assess adherence did, of course, differ somewhat between studies. Non-adherence was frequently intentional. More than half of non-adherence was to only one SPM, suggesting that interventions should target the particular drug for which adherence is problematic.

A number of modifiable barriers were identified. Among non-adherent patients, the most common underlying reasons were forgetfulness $(84.9 \%)$, worry that their SPM medicines will do more harm than good (33.8\%) and feeling hassled about their medicines (18.7\%). Many patients had multiple simultaneous barriers. These provide an essential framework for designing interventions that can improve adherence. We have shown elsewhere that a novel tool, which specifically screens for these and other modifiable barriers to adherence, can be successfully used in clinical practice-with resulting improvements in adherence and outcomes. ${ }^{26}$

In a multivariate analysis, increasing age and female sex were each associated with greater adherence. Previous studies have come to varying conclusions on the impact of age and sex on adherence. ${ }^{2027-29}$ While these factors are not modifiable, the uncertain correlation with adherence emphasises the need for clinicians to know their patients and tailor adherence interventions individually.

Polypharmacy has been previously identified as a major cause of non-adherence. ${ }^{30}$ However, in the multivariate analysis in the present study, taking a greater numbers of medicines was not associated with overall non-adherence. Better planning of medicines taking may have helped to prevent degradation of adherence in patients prescribed more drugs. ${ }^{31}$ Polypharmacy is also a proxy for more advanced disease and greater numbers of comorbidities, which could increase patients' appreciation of the necessity to maintain their health. Indeed, underlying diabetes was associated with reduced factor 1 (unintentional) non-adherence in the univariate analysis, which is perhaps not surprising given that these patients have prior experience of planned medicines taking. Overall, polypharmacy per se is not necessarily associated with non-adherence. However, polypharmacy was associated with factor 2 (intentional) non-adherence behaviourssuch as feeling hassled about sticking to the treatment plan or stopping medication due feeling worse when taking it. Interventions should, therefore, target the particular concerns that patients have about their polypharmacy. Our data align with previous work suggesting that poor experiences with treatment may predict intentional non-adherence ${ }^{32}$; by contrast, strong habit development (eg, from previous experience of planned medicines taking) can predict reduced unintentional adherence.

Individual SPMs were associated with variable levels of adherence, but only aspirin was identified in the multivariate analysis as being significantly associated with non-adherence. As identified by the SQ tool, aspirin was one of the most non-adhered to SPM, alongside statins. However, almost all patients were on statins, and hence statin use was not associated with non-adherence in the multivariate analysis. The high level of non-adherence to aspirin could be due to the familiarity of patients with this medicine and greater concern about its gastric side effects. Indeed, a review of major news items showed that concerns about the side effects of aspirin and statins were widely reported during the period of the study. With regard to statins, simvastatin and pravastatin (both shorter acting compared to atorvastatin and rosuvastatin) were the most commonly used agents at the time of the survey, both of which should be taken at night. Hence, the risk of forgetting these medicines may have been elevated among patients taking all other medicines once daily.

On the flip side, beta-blockers were associated with lower rates of factor 2 (intentional) non-adherence. This may have been due to the advice that is repeatedly given to patients prescribed beta-blockers ('Warning: Do not stop taking this medicine unless your doctor tells you to stop') or to symptomatic benefits making patients less likely to intentionally stop these medicines. In any case, patients were clearly selective about which SPMs they adhered to, and any interventions should therefore target the specific medicine(s) with which they have an issue.

In non-adherent patients, appreciation of the specific necessity for taking SPM was lower and specific concern 


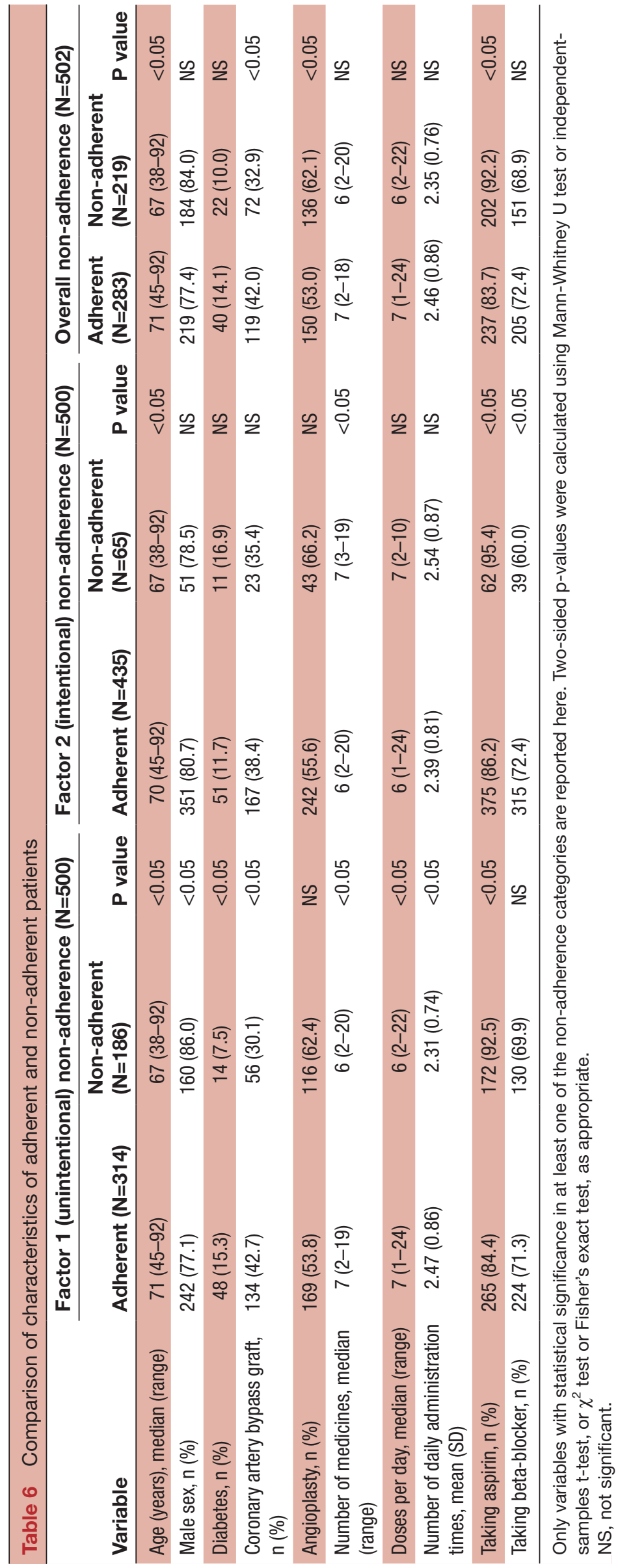


Table 7 Variables significantly associated with nonadherence in a multivariate logistic regression analysis

\section{Variables associated with non-} adherence

OR $(95 \% \mathrm{Cl})$

\begin{tabular}{ll}
\hline Factor 1 (unintentional) non-adherence $(\mathrm{N}=492)$ & \\
\hline Age (per 1 year) & $0.96(0.94$ to 0.98$)$ \\
\hline Female sex & $0.50(0.29$ to 0.82$)$ \\
\hline Diabetes & $0.44(0.23$ to 0.85$)$ \\
Previous coronary artery bypass graft & $0.60(0.40$ to 0.90$)$ \\
\hline Prescribed aspirin & $2.00(1.05$ to 3.85$)$ \\
Specific concern about SPM & $1.08(1.03$ to 1.13$)$
\end{tabular}

Factor 2 (intentional) non-adherence $(\mathrm{N}=480)$

\begin{tabular}{ll}
\hline $\begin{array}{l}\text { Age (per } 1 \text { year) } \\
\begin{array}{l}\text { Number of prescribed medicines (per one } \\
\text { drug) }\end{array}\end{array}$ & 0.96 (0.93 to 0.99$)$ \\
\hline $\begin{array}{l}\text { Prescribed beta-blocker } \\
\text { Prescribed aspirin }\end{array}$ & $0.48(0.25$ to 1.31$)$ \\
\hline Specific necessity for SPM & $4.60(1.25$ to 16.96$)$ \\
\hline Specific concern about SPM & $0.90(0.82$ to 0.99$)$ \\
\hline Issues with repeat prescriptions & $1.16(1.07$ to 1.27$)$ \\
\hline Overall non-adherence (N=484) & $3.68(1.75$ to 7.74$)$ \\
\hline Age (per 1 year) & \\
\hline Female sex & $0.96(0.94$ to 0.98$)$ \\
\hline Prescribed aspirin & $0.56(0.34$ to 0.93$)$ \\
\hline Specific concern about SPM & $2.22(1.18$ to 4.17$)$ \\
\hline Issues with repeat prescriptions & $1.12(1.07$ to 1.18$)$ \\
\hline
\end{tabular}

The SPM specific concern and specific necessity is per unit of average score according to $B M Q$ scale.

SPM, secondary prevention medicine.

about taking SPM was higher than adherent individuals. These factors were also associated with factor 2 (intentional) non-adherence in the multivariate analysis, but only specific concern about SPM was associated with overall non-adherence. The association of specific concern about SPM with factor 1 (unintentional) non-adherence suggests that forgetfulness is affected to some extent by underlying beliefs about medicines and may not be wholly unintentional. This aligns with previous data from a study of 24000 patients with chronic disease, which found that greater concern about medication was a significant predictor of forgetting to take it. ${ }^{33}$ Lower belief in the specific necessity for taking SPM was not associated with overall non-adherence but was linked with greater intentional non-adherence. This finding is consistent with a recent meta-analysis, which found no correlation between necessity beliefs and overall medicines adherence among patients with cardiovascular disease. ${ }^{34}$ The authors of the meta-analysis further concluded that the relationship between overall medicines adherence and concern beliefs is stronger than the relationship between adherence and necessity beliefs among patients with cardiovascular disease. ${ }^{34}$ In these patients, alleviating concerns may be a more impactful intervention than emphasising benefit.

Practical problems with opening medicines' containers, reading labels, swallowing medicines or getting repeat prescriptions may also be important contributors to non-adherence-in particular to intentional non-adherence. The multivariate analysis demonstrated that difficulties with getting repeat prescriptions had a strong association with all types of non-adherence and should be a major area for intervention when identified.

Among other factors, angioplasty was associated with non-adherence in the univariate (but not the multivariate) analysis. This might have been due to exaggerated expected benefits among patients undergoing this procedure. ${ }^{35}{ }^{36}$ Perceptions about previous procedures should be taken into account when devising interventions.

The cost of medicines is considered to be a potential barrier to adherence. ${ }^{513}$ In the present study, prescription charges were a reason for non-adherence in almost $30 \%$ of non-adherent patients on whom they were levied, although this was a relatively small group. The elimination of all costs is not necessarily associated with significantly improved adherence. ${ }^{37}$

More generally, the survey used in this study was well received by patients and had a high response rate $(72.3 \%)$. This may have been due to its patient-centred approach. The detailed responses provided by many individuals demonstrate a strong interest in talking about their medicines, although the recruitment process may have identified a particularly highly motivated sample. Regardless, the domains explored provided useful practical information for conducting a patient-tailored medicines review. Qualitative research has suggested that a key focus of these interactions should be on improving understanding and alleviating concerns about prescribed medicines (with the amount and level of information tailored to individual needs), and understanding beliefs around the illness and medicines taking to help decide whether such factors may influence adherence decisions. ${ }^{38}$

The various adherence tools used did not provide entirely concordant information on propensity for or actual non-adherence. Used singly, none of the tools would have been sufficient to reveal all the information required to facilitate a complete review of patient needs. In addition, non-adherence behaviour was not 'all or nothing' and patients could be adherent to one medicine and not others. ${ }^{22}$ This emphasises the need for healthcare professionals to know their patients and to screen frequently for intentional and unintentional non-adherence, including barriers and modifiable factors that can lead to this behaviour. Concerns and difficulties with taking medicines should be addressed even in patients who are apparently adherent.

We must acknowledge some important limitations of the present study. Most importantly, it was based on self-reports of adherence; social desirability and memory biases may lead to overestimation of adherence by patients. However, the adherence rate obtained was broadly in line 
with previous studies. ${ }^{6-10}$ In addition, adherence changes over time and shifting beliefs about medicines can often underlie this: over the first year of treatment, around a fifth of patients may experience a significant increase in concern about their medicines. ${ }^{39}$ It would, therefore, be valuable to reassess our data over additional time points. Finally, this was a single-centre study and hence the results may not be applicable across all settings.

Overall, we conclude that, when appropriately prompted, patients will share actual and potential modifiable barriers to adherence that can be addressed in clinical practice. Healthcare professionals should elicit and explore their patients' beliefs and experiences with their medicines, and tailor adherence interventions individually to overcome barriers.

Acknowledgements We thank Dr Timothy Ryder from Biological Communications for editorial assistance in drafting the manuscript. The service was paid for by Leeds Teaching Hospitals NHS Trust. Use of the CMMAS is protected by US copyright laws. Permission for use is required. A license agreement is available from: Donald E Morisky, Department of Community Health Sciences, UCLA School of Public Health, Los Angeles, California, USA. The Adherence Estimator is a trademark of Merck \& Co., Whitehouse Station, New Jersey, USA. Copyright @2008 Merck \& Co, Inc. All rights reserved.

Contributors The study was led by RK with the support of the supervisors, data collection and administrative support, which included all the coauthors. The design of the study and the questionnaire, and ethics applications were done by RK with the support of KM, JS, ASH. Postage and data collection were with the help of CF. Data analysis was led by RK. All planning and findings were presented to and discussed by the authors. The manuscript was drafted by the lead author and reviewed and adjusted based on suggestions from all the coauthors. All authors gave final approval and agreed to be accountable for all aspects of the work. All revisions were made by the lead author and coauthors reviewed and commented were appropriate.

Funding The study was partially funded by the Leeds Teaching Hospitals Charitable Foundation.

Competing interests None declared.

Patient consent for publication Not required.

Ethics approval The study was approved by the NHS Leeds (Central) Research Ethics Committee (reference number 09/H1313/62) and by the University of Bradford Ethics Committee. All patients provided written informed consent to participate.

Provenance and peer review Not commissioned; externally peer reviewed.

Data availability statement All data relevant to the study are included in the article.

Open access This is an open access article distributed in accordance with the Creative Commons Attribution Non Commercial (CC BY-NC 4.0) license, which permits others to distribute, remix, adapt, build upon this work non-commercially, and license their derivative works on different terms, provided the original work is properly cited, appropriate credit is given, any changes made indicated, and the use is non-commercial. See: http://creativecommons.org/licenses/by-nc/4.0/.

\section{REFERENCES}

1. National Institute for Health and Care Excellence. MI - secondary prevention: Secondary prevention in primary and secondary care for patients following a myocardial infarction. Clinical Guideline 172, 2013. Available: www.nice.org.uk/guidance/cg172 [Accessed 31 Aug 2018].

2. Members TF, Montalescot G, Sechtem U, et al. ESC guidelines on the management of stable coronary artery disease. Eur Heart $J$ 2013;34:2949-3003.

3. Amsterdam EA, Wenger NK, Brindis RG, et al. ACC/AHA guideline for the management of patients with non-ST-elevation acute coronary syndromes: A report of the American College of
Cardiology/American Heart Association Task Force on Practice Guidelines. Circulation 2014;2014:e344-426.

4. Ho PM, Magid DJ, Shetterly SM, et al. Medication nonadherence is associated with a broad range of adverse outcomes in patients with coronary artery disease. Am Heart J 2008;155:772-9.

5. National Institute for Health and Care Excellence. Medicines adherence: Involving patients in decisions about prescribed medicines and supporting adherence. Clinical Guideline 76, 2009. Available: www.nice.org.uk/guidance/cg76 [Accessed 31 Aug 2018].

6. Kolandaivelu K, Leiden BB, O'Gara PT, et al. Non-adherence to cardiovascular medications. European Heart Journal 2014;35:3267-76.

7. World Health Organization. Adherence to long-term therapies: Evidence for action, 2003. Available: www.who.int/chp/knowledge/ publications/adherence_report/en/ [Accessed 31 August 2018].

8. Jackevicius CA, Li P, Tu JV. Prevalence, predictors, and outcomes of primary nonadherence after acute myocardial infarction. Circulation 2008;117:1028-36.

9. Rathore SS, Mehta RH, Wang Y, et al. Effects of age on the quality of care provided to older patients with acute myocardial infarction. Am J Med 2003;114:307-15.

10. Chodick G, Shalev V, Gerber Y, et al. Long-term persistence with statin treatment in a not-for-profit health maintenance organization: a population-based retrospective cohort study in Israel. Clin Ther 2008;30:2167-79.

11. Horwitz RI, Viscoli CM, Donaldson RM, et al. Treatment adherence and risk of death after a myocardial infarction. The Lancet 1990;336:542-5.

12. Chowdhury R, Khan $\mathrm{H}$, Heydon $\mathrm{E}$, et al. Adherence to cardiovascular therapy: a meta-analysis of prevalence and clinical consequences. Eur Heart $J$ 2013;34:2940-8.

13. Horne R, Weinman J, Barber N, et al. Concordance, adherence and compliance in medicine taking. Report for the National Co-ordinating Centre for NHS Service Delivery and Organisation R \& D (NCCSDO), 2005. Available: www.netscc.ac.uk/hsdr/files/project/SDO_FR_081412-076_V01.pdf [Accessed 31 Aug 2018].

14. Garber MC, Nau DP, Erickson SR, et al. The concordance of selfreport with other measures of medication adherence: A summary of the literature. Med Care 2004;42:649-52.

15. DiMatteo MR. Variations in patients' adherence to medical recommendations: A quantitative review of 50 years of research. Med Care 2004;42:200-9.

16. Shi L, Liu J, Fonseca V, et al. Correlation between adherence rates measured by MEMS and self-reported questionnaires: a metaanalysis. Health Qual Life Outcomes 2010;8.

17. Roter DL, Hall JA, Merisca R, et al. Effectiveness of Interventions to Improve Patient Compliance. Medical Care 1998;36:1138-61.

18. Nieuwlaat R, Wilczynski N, Navarro T, et al. Interventions for enhancing medication adherence. Cochrane Database Syst Rev 2014;22.

19. Kripalani S, Yao X, Haynes RB. Interventions to Enhance Medication Adherence in Chronic Medical Conditions. Arch Intern Med 2007;167:540-50.

20. Gehi AK, Ali S, Na B, et al. Self-reported medication adherence and cardiovascular events in patients with stable coronary heart disease. Arch Intern Med 2007;167:1798-803.

21. Morisky DE, Ang A, Krousel-Wood M, et al. Predictive validity of a medication adherence measure for hypertension control. J Clin Hypertens 2008;10:348-54.

22. McHorney CA. The Adherence Estimator: a brief, proximal screener for patient propensity to adhere to prescription medications for chronic disease. Curr Med Res Opin 2009;25:215-38.

23. Horne R, Weinman J. Patients' beliefs about prescribed medicines and their role in adherence to treatment in chronic physical illness. $J$ Psychosom Res 1999;47:555-67.

24. Field AP. Discovering Statistics Using IBM SPSS Statistics: And Sex and Drugs and Rock ' $n$ ' Roll. London, UK: Sage Publications Ltd, 2009.

25. Marston L. Introductory Statistics for Health and Nursing Using SPSS. London, UK: Sage Publications Ltd, 2010.

26. Khatib R, Patel N, Laverty U, et al. Re-engineering the postmyocardial infarction medicines optimisation pathway: a retrospective analysis of a joint consultant pharmacist and cardiologist clinic model. Open Heart 2018;5:e000921.

27. Granger BB, Ekman I, Granger CB, et al. Adherence to medication according to sex and age in the CHARM programme. Eur $J$ Heart Fail 2009;11:1092-8.

28. Doggrell S. Adherence to medicines in the older-aged with chronic conditions: Does an intervention concerning adherence by an allied health professional help? Drugs Aging 2010;27:239-54. 
29. Rolnick S, Bruzek R, Pawloski P, et al. PS2-33: Patient characteristics associated with medication adherence. Clinical Medicine \& Research 2011;9.

30. Avorn J. Polypharmacy - a new paradigm for quality drug therapy in the elderly? Arch Intern Med 2004;164:1957-9.

31. Shalansky SJ, Levy AR, Ignaszewski AP. Self-reported Morisky score for identifying nonadherence with cardiovascular medications. Ann Pharmacother 2004;38:1363-8.

32. Alison Phillips L, Leventhal H, Leventhal EA. Assessing theoretical predictors of long-term medication adherence: Patients' treatment-related beliefs, experiential feedback and habit development. Psychology \& Health 2013;28:1135-51.10.1080/08870446.2013.793798

33. Gadkari AS, McHorney CA. Unintentional non-adherence to chronic prescription medications: How unintentional is it really? BMC Health Serv Res 2012;12.
34. Foot H, La Caze A, Gujral G, et al. The necessity-concerns framework predicts adherence to medication in multiple illness conditions: A meta-analysis. Patient Educ Couns 2016;99:706-17.

35. Ozkan O, Odabası J, Ozcan U. Expected treatment benefits of percutaneous transluminal coronary angioplasty: the patient's perspective. Int J Cardiovasc Imaging 2008;24:567-75.

36. Chandrasekharan DP, Taggart DP. Informed consent for interventions in stable coronary artery disease: problems, etiologies, and solutions. Eur J Cardiothorac Surg 2011;39:912-7.

37. Choudhry NK, Avorn J, Glynn RJ, et al. Full coverage for preventive medications after myocardial infarction. $N$ Engl $J$ Med 2011;365:2088-97.

38. Lehane E, McCarthy G, Collender V, et al. Medication-taking for coronary artery disease - patients' perspectives. Eur J Cardiovasc Nurs 2008;7:133-9.

39. Allen LaPointe NM, Ou F-S, Calvert SB, et al. Changes in beliefs about medications during long-term care for ischemic heart disease. Am Heart J 2010;159:561-9. 